\title{
AS PRÁTICAS CIRCENSES E A RELAÇÃO DO CORPO DA CRIANÇA EM SITUAÇÃO DE RUA NO MUNDO
}

\author{
Ranulfo Cavalari Neto
}

\begin{abstract}
Resumo: O artigo tem o objetivo de narrar uma experiência com as práticas corporais e crianças e adolescentes em situação de rua, a partir da ótica do corpo, da corporeidade e dos processos escolares encontrados na leitura da "pedagogia da diferença." Ao propor a oficina abre-se uma oportunidade de abrir o debate sobre as práticas corporais das crianças e adolescentes, e que nesse caso, alguns se utilizam como forma de trabalho pelas ruas e sinaleiras das cidades. A cultura da rua, ou melhor a cultura de viver na rua faz marcas no corpo e interfere no processo de desenvolvimento do ser humano. A corporeidade de uma criança em situação de rua deve ser observada com um olhar cuidadoso adotando a pedagogia da diferença, de modo que promova corpos potentes, criativos, alegres e livres.
\end{abstract}

Palavras-chave: Criança e adolescente em situação de rua; Corporeidade; Pedagogia da diferença.

Resumen: El artículo pretende narrar una experiencia con prácticas corporales y niños y adolescentes de la calle, desde la perspectiva del cuerpo, la corporeidad y los procesos escolares que se encuentran en la lectura de la 'pedagogía de la diferencia'. El taller abre una oportunidad para abrir el debate sobre las prácticas corporales de niños y adolescentes, y en este caso, algunas se utilizan como una forma de trabajar por las calles y señales de las ciudades. La cultura de la calle, o más bien la cultura de vivir en la calle, deja marcas en el cuerpo e interfiere en el proceso de desarrollo humano. La corporeidad de un niño de la calle debe observarse con atención, adoptando la pedagogía de la diferencia, para que promueva cuerpos poderosos, creativos, felices y libres.

Palabras clave: Niño y adolescente de la calle; Corporeidad; Pedagogía de la diferencia.

$\mathrm{O}$ artigo tem o objetivo de narrar uma experiência com as práticas corporais e crianças e adolescentes em situação de rua, a partir da ótica do corpo, da corporeidade e dos processos escolares encontrados na leitura específica de alguns textos. Em seguida deixar mais claro que as práticas pedagógicas devem ter o papel de desestabilizar e desconstruir a naturalidade, a universidade e a unidade do centro, ou do dito "normal”, como nos convoca a refletir Louro (2003). Do mesmo modo, a autora Trindade (2002) coloca a "pedagogia da diferença" como concepção de educação que acolhe e respeita as diferenças.

O projeto Ocupa Praça ${ }^{\text {ii }}$ foi planejado bimestralmente e ocorria sempre na segunda quarta-feira do mês na Praça Vital Brazil, em Icaraí na cidade de Niterói-RJ. Em um dos vários planejamentos do Ocupa Praça foi proposto a realização de uma oficina de práticas circenses. 


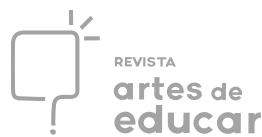

Esse projeto é pensado para os usuários infanto-juvenil da rede de saúde mental do município de Niterói. O público alvo da oficina seria as crianças e adolescentes em situação de rua que são acompanhadas pelos equipamentos da rede de atenção psicossocial de Niterói, além das crianças vinculadas ao Centro de Atenção Psicossocial Infanto-Juvenil (CAPSi) e Equipe de Referência Infanto-juvenil para Ações de Atenção ao Uso de Álcool e outras drogas (ERIJAD).

Ao propor a oficina abre-se uma oportunidade de abrir o debate sobre as práticas corporais das crianças e adolescentes, e que nesse caso, alguns se utilizam como forma de trabalho pelas ruas e sinaleiras das cidades. Também foi a oportunidade de pensar junto da equipe as formas de resistência e de existir no mundo que essas crianças desenvolveram. Nesse contexto, essa produção abrirá caminhos para se pensar nesses corpos que vivem na rua e estão fora do sistema escolar, portanto pensar nesses processos são importantes para compreender o modo que a sociedade se estruturou (base no racismo estrutural).

Assim, de forma idealizada e com um pouco de medo de, talvez, não despertar o interesse do público alvo, planejei a seguinte metodologia: $1^{\circ}$ Momento: acolhida e conversa inicial sobre o que eles conheciam e pensavam sobre o circo e suas manifestações, dispostos sentados em um tapete colorido sob a sombra de uma árvore na praça; $2^{\circ}$ Momento: exploração e confecção dos materiais; e $3^{\circ}$ Momento: experimentação do material (bolinhas de malabares e Rola-Rola).

Esses momentos foram importantes enquanto organização metodológica, porém o que mais estava interessado era no "como" as crianças iriam reagir, e dessa forma, construir o vínculo necessário para o acompanhamento dessas crianças. Eles adoraram a experiência de fazer as bolinhas dos malabares, devido ao uso de materiais não convencionais (balões e semente de passarinho). Fiquei muito impressionado quando as crianças e adolescentes mostraram toda a sua habilidade ao fazer diversas manobras com as bolinhas. Já os adolescentes mais velhos, se aproximavam aos poucos e logo, já estavam sentados para a conversa, construção e experimentação das práticas circenses.

Nesse momento percebi que as práticas corporais são muito potentes como experiência humana para esse público específico. Devido às situações de vida na rua que são sempre rápidas e urgentes, eles apresentam dificuldades em atividades que exijam muito atenção, foco e equilíbrio. O que não impossibilita as práticas circenses, aliás, o direito de experimentar seu corpo de uma outra forma.

Para além da dimensão do aprender-fazer presente nas oficinas de modo geral, também existe a dimensão do aprender a conviver e do aprender a ser. Esses corpos se movimentam de Revista Interinstitucional Artes de Educar. Rio de Janeiro, V. 7, N. 1 - pág. 45-59 janeiro-abril de 2021: "Pedagogias Vitais: Corpo, Desejo e Educação" DOI: 10.12957/riae.2021.54954 


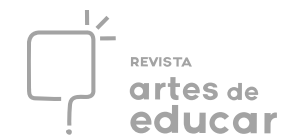

maneira específica adquirida como forma de sobrevivência e proteção, pois todos sabemos os riscos de viver na rua, a convivência com atores diferentes de sua realidade cotidiana traz novos vínculos e pode produzir uma dinâmica com o território mais afetivo e menos reativo. Durante as oficinas as conversas sobre a vida e a existência no território são estimuladas, e assim o aprender a ser vem dominando o espaço, não por meio de conselhos, dicas e prescrições, mas por meio da escuta sensível e acolhedora. Muitas vezes, apenas permitindo a escuta, é a chave para que juntos refletimos sobre essa existência no mundo, pensando nas alegrias e nas tristezas que nos permeiam a todo instante.

Também quero narrar uma situação bem curiosa nessa oficina, quando eu pergunto o nome de uma das crianças e recebo o nome de Ruan (nome fictício), mas no momento seguinte outras vozes discordam e confrontam dizendo: - Não é Ruan, é Luana ou Lua ((nome fictício))!

Confesso que fiquei confuso, e por alguns minutos pensando naquela situação. Após algum tempo conversando com outros profissionais me dei conta do que parece significar um corpo feminino vivendo na rua, ou das consequências e do risco aumentado que isso proporciona. A violência sexual é algo presente para as pessoas em situação de rua, uma criança ou adolescente nessa situação corre maiores riscos devido sua vulnerabilidade.

A saída que Lua encontrou para se proteger foi mudar seu nome para Ruan, mudando seus cabelos longos por cabelos curtos, vestir camisetas largas e bermudas masculinas. Como proteção utiliza o nome Ruan quando encontra desconhecidos, no entanto quando é estabelecido algum vínculo ela conta sua história e solicita ser chamada de "Lua", uma menina negra de 15 anos que está em situação de rua desde muito jovem. O debate sobre o gênero, principalmente a violência contra a mulher necessitam ser tema em todos os espaços de discussão e formação acadêmica.

Louro (2003) destaca que para o campo educacional, trabalhar a afirmação desses grupos (minorias) é considerado como profundamente perturbadora. Não dispomos de referências ou de tradições para lidar com os desafios aí implicados, além disso, o debate sobre gênero e sexualidade é abafado na família, na escola; já na igreja é pautado no viés de desvio do "bom caminho" de forma punitiva e excludente. A autora crítica a conduta, enquanto educadores, de simplesmente "encaminhá-los" para os serviços de orientação psicológica para que sejam corrigidos, nem podemos aplicar-lhes um sermão para que sejam reconduzidos ao "bom caminho". 


\section{O processo de exclusão da escola e da sociedade}

Primeiro, quero esclarecer que nenhuma criança ou adolescente em situação de rua é de rua ou surgiu da rua. Todas vieram de famílias que de alguma forma não conseguiram proporcionar segurança a elas. Além de tudo a criança e adolescente em situação de rua é um fato de que as políticas sociais não estão conseguindo proteger os direitos da criança e do adolescente estabelecido pelo Estatuto da Criança e do Adolescente (ECA).

No texto da Trindade (2002) o corpo é a presença concreta no mundo, porque veicula gestos, expressões e comportamentos das ações individuais e coletivas de um grupo. O grupo de crianças e adolescentes em situação criam diversas formas de sobrevivência na rua, desde a roupa, o cheiro, os gestos corporais, o modo como anda e as atitudes que reagem com tanto sofrimento na rua. Além disso, eles se agrupam em coletivos que se protegem e cuidam uns dos outros. Existe um imaginário sobre a população em situação de rua, de que todos eles fazem uso de drogas, roubam, furtam e se prostituem, porém isso não é verdade. Muitos deles são trabalhadores informais (catadores, guardadores de veículos, vigias e etc) ou pedintes, o álcool e outras drogas entram no cenário para acalentar o sofrimento frequente e cotidiano da invisibilidade que os acometem.

O texto "Do corpo da carência ao corpo da potência", de Azoilda Trindade (2002), possui o seguinte questionamento: com que corpos estamos comprometidos - com corpos potentes, criativos, alegres, livres, ou com corpos aprisionados, silenciados, podados, covardes, tiranizados e tiranos? Posto o cenário atual nacional e estadual do Rio de Janeiro e minha experiência na rede de saúde mental de Niterói tenho a impressão que são corpos aprisionados e silenciados. Logo estão sendo produzidos a cada dia, no momento em que estereotipamos e estigmatizamos a população em situação de rua.

As crianças em situação de rua foram estigmatizadas de "pivetes", "vagabundos” ou "bandidos”, dentro de um contexto social opressor e repressor da vida do pobre, negro e periférico, autorizado pelo Estado que financia e reforça práticas higienistas nos centros urbanos. A partir do momento que essas crianças, adolescentes e jovens começam a incomodar a sociedade, em bairros de classe média alta, a polícia entra em ação. A assistência social e a saúde não consegue chegar a essa população em meio a tanta precarização. A educação já os abandonou desde o momento que foram considerados como "evadidos" da escola. A escola é o primeiro local que a criança em situação de rua evade, depois dessa instituição ela evade da família, e encontra na rua uma nova forma de sobreviver. 


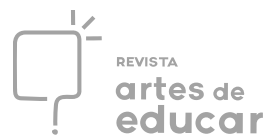

Em primeiro lugar, eu gostaria de recusar o conceito de evasão. As crianças populares brasileiras não se evadem da escola, não a deixam porque querem. As crianças populares brasileiras são expulsas da escola- não, obviamente, porque esta ou aquela professora, por uma questão de antipatia pessoal, expulse estes ou aqueles alunos ou os reprove. É a estrutura mesmo da sociedade que cria uma série de impasses e dificuldades, uns em solidariedade com os outros, de que resultam obstáculos enormes para as crianças populares não só chegarem à escola, mas também, quando chegam, nela ficarem e nela fazerem o percurso a que têm direito. (FREIRE, 2006, p. 35)

Um exemplo, para adentrarmos no campo educacional, é a utilização ampla e sem críticas do termo "evasão escolar" por grande parte dos gestores, professores e comunidade escolar. Em diversas passagens pela obra de Paulo Freire, é possível encontrar referências ao processo de evasão escolar, contextualizando de forma mais aproximada seu significado no cenário de opressão. Defendemos que o acesso e permanência dessas crianças fazem parte de um percurso na qual elas têm o direito de viver.

Nesse sentido, em uma realidade onde crianças e adolescentes das classes populares estão afastados da escola também tomamos a rua como espaço de práticas educativas, na perspectiva da educação não-formal e informal. A partir da realidade mexicana, foi estudado alternativas ao ensino tradicional, Saucedo e Taracena (2011) propõem um entendimento de que os aprendizados das crianças na rua não podem e nem devem ser descartados, visto que pode causar desinteresse pela reintegração à escola.

Ainda que estar na escola seja um direito social, garantido pelo Estatuto da Criança e do Adolescente (ECA), é fato que sua promulgação, em 1990, não foi suficiente, uma vez que ainda há muitos desafios na implementação de políticas públicas. Esses sujeitos, que deveriam estar sobe a proteção da família, do Estado e da sociedade em algum momento de sua história passaram pela escola e por motivos diversos a escola e os atores que a constituem deixaram de serem presentes.

O Estatuto, em seu artigo 100, determina a proteção integral e prioritária, sem discriminação, para todas as crianças e adolescentes, como prioridade absoluta do Estado e da sociedade. No entanto, ao enxergarmos crianças e adolescentes vivendo nas ruas, percebemos que o Sistema de Garantia de Direitos ainda precisa ser consolidado, e não apenas em relação ao Estado, mas à sociedade em geral. É fato que, de alguma maneira (algumas mais explícitas que outras), reproduzimos ou legitimamos as desigualdades sociais. 
"Professoras e professores que optam pela pedagogia da falta, da carência, da falta, ou por uma pedagogia da potência, da diversidade, das diferenças" (TRINDADE, 2002, p. 72). Os profissionais da saúde e da educação precisam verificar em suas práticas cotidianas qual a pedagogia que estão adotando na abordagem de crianças e adolescentes em situação de vulnerabilidade social e com crianças e adolescentes em situação de rua, assim como olhar de modo diferenciado para suas famílias que também necessitam de um suporte humano, solidário e de garantia dos direitos humanos.

Por isso, acredito que as práticas corporais que dialogam com esse público é importante serem visibilizadas. O jogo, o futebol, a prática circense são práticas corporais que as crianças e adolescentes em situação de rua veem aproximação com sua história de vida. Cabe ao profissional/professor utilizá-los na perspectiva da pedagogia da potência e não da repetição e cópia alienada e alienante.

Acredito na escola como ambiente potente que pode junto com outras políticas públicas sociais fazer com que a criança e o adolescente permaneçam "protegidos" e exercendo sua cidadania com liberdade. A realidade violenta das cidades impede que utilizemos o termo protegido sem as aspas, principalmente o Rio de Janeiro em plena intervenção militar que massacram as pessoas que vivem em comunidades e favelas com inúmeros exemplos.

A produção da diferença como algo que precisa ser eliminado e não aceito é reforçado por discursos que estão presentes em muitas instituições. Louro (2003) coloca que não apenas na escola, mas também na mídia, no cinema, nas campanhas de saúde, nos informes médicos produzem a lógica de um certo padrão a ser adotado por todas e todos. O caso da Lua é um deles, a dificuldade e o perigo de viver na rua levou nesse caso específico uma menina a se vestir e se comportar como um menino em situação de rua. A adolescente de 15 anos conta que fez isso por questões de segurança. "No corpo estão escritos todas as regras, todas as normas e todos os valores de uma sociedade específica, por ser ele o meio de contato primário do indivíduo com o ambiente que o cerca" (DAOLIO, 1995, p. 39). Por fim, precisamos olhar, urgentemente, para a realidade brasileira através do quantitativo de casos de violência contra a mulher, os casos de feminicídio e os casos de intolerância e descriminação e identificar quais as racionalidades predominantes. Ninguém é alguma coisa, no sentido fixo da coisa, somos sujeitos em transformação a todo o momento e em constante movimento, se admitimos que algo precisa ser modificado, precisamos agir em prol de um mundo que admita a diferença na direção do centro e das extremidades. 


\section{O corpo na rua}

A cultura da rua, ou melhor a cultura de viver na rua produz marcas e cicatrizes no corpo e interfere no processo de desenvolvimento do ser humano. Daolio (1995) escreve que não é possível separar os componentes biológicos e socioculturais, um afetando o outro igualmente, quando se fala no desenvolvimento da natureza do homem. O cérebro humano é também cultural, já que sofre uma influência importante por atitudes culturais. Quando associamos essas ideias as pessoas em situação de rua ficam evidente a relação, colaborando para se considerar a existência de uma cultura da e na rua.

Na obra de Daolio (1995), ele faz uma referência ao pensador Marcel Mauss que foi o primeiro a estudar o corpo e o que chamamos de "técnicas corporais" nos estudos antropológicos. Mauss (1974 apud DAOLIO, 1995) coloca que os gestos e os movimentos corporais são técnicas criadas pela cultura, passíveis de transmissão através das gerações e imbuídas de significados específicos. Dessa forma podemos pensar na prática circense e na diferença de significado que ela possui nas infâncias, por exemplo, trazendo recortes raciais e socioeconômicos.

Podemos pensar que $L u a$, sofreu um processo de inCORPOração, conceito explicado por Daolio (1995), o homem, por meio do seu corpo, vai assimilando e se apropriando dos valores, normas e costumes sociais.

Daolio (1995) nos convoca a pensar em qual apropriação de corpo o professor de educação física tem em sua prática docente. A apropriação de corpo no papel de professor de educação física que pensa o setor saúde e educação é sensível aos valores, conceitos, conteúdos e métodos com os quais trabalho. Nas intervenções com crianças e adolescentes em situação de rua, junto a uma equipe multiprofissional, procura estabelecer essas relações de sentido entre as técnicas corporais que eles e elas possuem e vincular aos conteúdos das práticas corporais, com o objetivo de oferecer um cuidado diferenciado em saúde.

\section{Os corpos dóceis e in(visíveis)}

A descoberta do corpo como objeto e alvo de poder, foi o que estudou Foucault em análises do século XVII e XVIII. Esse controle sobre o corpo vai ser efetivamente disciplinarizado por meio de instituições como a escola, o hospital e o exército. Esse é um Revista Interinstitucional Artes de Educar. Rio de Janeiro, V. 7, N. 1 - pág. 45-59 janeiro-abril de 2021: "Pedagogias Vitais: Corpo, Desejo e Educação" DOI: 10.12957/riae.2021.54954 


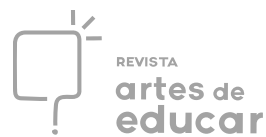

recorte importante do texto de Olivier (2000), no qual me fez refletir sobre a população em situação de rua e a política de repressão da prefeitura de Niterói ao realizar internações compulsórias de crianças e adolescentes para um hospital psiquiátrico do município. Nesses momentos os corpos dessas crianças e adolescentes são retirados com violências para veículos da assistência social e levados ao hospital. Demonstrando que o poder público não quer que eles continuem na rua, prejudicando a ordem e limpeza das ruas de Icaraí (bairro nobre de Niterói).

Utilizaram da violência e do medo para que as crianças migrassem para outros locais da cidade e deixassem limpo a zona nobre da cidade. A política municipal escolhe essa forma de trabalho visando diminuir a população infanto-juvenil em situação de rua. Não por acaso todos as crianças e adolescentes em situação de rua que já participaram do Ocupa Praça eram negras. As pessoas que estão no poder querem docilizar esses jovens corpos negros da rua. Nesse sentido o seguinte trecho completa sobre tal docilização dos corpos: "A disciplina fabrica assim corpos submissos e exercitados, corpos "dóceis". A disciplina aumenta as forças do corpo (em termos econômicos) e diminui essas mesmas forças (em termos de obediência)" (FOCAULT, 1979, p. 127 apud OLIVIER, 2000, p. 44 ).

Nesse sentido o Ocupa Praça por meio da ocupação dos territórios na comunidade enfrenta esse terrorismo produzido pelo Estado com encontros potentes entre sujeitos, utilizando de práticas diversas que acolha e cuide do diferente, entendendo que em cada corpo possui uma história que foi produzida a partir de um mundo.

Olivier (2000) diz que o que marca o ser humano são relações dialéticas entre o corpo, a alma e o mundo. Olhando o corpo através de sua corporeidade (unidade expressiva da existência). As práticas circenses emergem desse olhar sobre a corporeidade das crianças e adolescentes em situação de rua. Tais práticas parece contribuir para que essas crianças e adolescentes sintam novamente a capacidade de criação e produção de algo inédito a elas. A forma como elas se apropriam do desafio e o transforma parece modificar um mundo infinito de possibilidades trazendo potência e ressignificação. A corporeidade se refaz a todo momento e as práticas circenses são possibilidades, trazidas por meio do desejo individual e coletivo, de reinvenção por meio do corpo que vai muito além dos malabares, e por uma questão de foco e aprofundamento do artigo não será ampliado.

O conceito chave do texto de Olivier (2000) é o de corporeidade. Segue abaixo o trecho que melhor explica o conceito e a relação com o mundo: 
O corpo humano, como corporeidade - como permanência que se constrói no emaranhado das relações sócio-históricas e que traz em si a marca da individualidade - não termina nos limites que a anatomia e a fisiologia lhe impõem. Ao contrário, estende-se por meio da cultura, das roupas e dos instrumentos criados pelo homem. O corpo confere-lhes um significado e sua utilização passa por um processo de aprendizagem construtor de hábitos.

Pode-se entender melhor as relações da população em situação de rua com a sociedade. As intenções tem papel importante nas diferentes formas de estar no mundo. Dependendo da situação um mesmo corpo pode assustar e afastar ou ser doce e sedutor, as crianças e adolescentes em situação de rua estão dentro dessa lógica. Os hábitos que os cercam são construídos de acordo com as relações que eles estabelecem com a comunidade no qual estão inseridos, como comerciantes, moradores, instituições de saúde, igrejas e etc.

\section{A rua e a educação}

Muitos movimentos foram necessários para que a população em situação de rua fosse minimamente enxergada pelas políticas públicas. Nesse caminho muitas confusões conceituais foram colocadas em questão, de acordo com os interesses políticos. Como subsídio a formulação de um conceito para "criança e adolescente em situação de rua" foram utilizados documentos como a Política Nacional para a Inclusão da População em Situação de Rua de 2008, a Campanha Nacional Criança Não é de Rua de 2010, e a discussão do Comitê Nacional de Atenção à Criança e ao Adolescente em Situação de Rua em 2014. Atualmente se entende que crianças e adolescentes em situação de rua são:

Sujeitos em desenvolvimento com direitos violados, que utilizam logradouros públicos, áreas degradadas como espaço de moradia ou sobrevivência, de forma permanente e/ou intermitente, em situação de vulnerabilidade e/ou risco pessoal e social pelo rompimento ou fragilidade do cuidado e dos vínculos familiares e comunitários, prioritariamente situação de pobreza e/ou pobreza extrema, dificuldade de acesso e/ou permanência nas políticas públicas, sendo caracterizados por sua heterogeneidade, como gênero, orientação sexual, identidade de gênero, diversidade étnico-racial, religiosa, geracional, territorial, de nacionalidade, de posição política, deficiência, entre outros (BRASIL, 2017, p. 27).

Nesta pesquisa trataremos de crianças, adolescentes e jovens em situação de rua e/ou vulnerabilidade, a inclusão do termo "vulnerabilidade" demarca uma ampliação da situação de 
marginalidade, vivenciada não só pelos sujeitos que vivem nas ruas, mas por aqueles que por algum momento passaram por ela, culminando na zona de desfiliação ${ }^{\mathrm{iii}}$.

A vulnerabilidade é entendida, por Robert Castel (2004) não como um estado de falta (alimentação, moradia, saúde, educação) mas pelo efeito de dois vetores: o eixo de integração ou não integração pelo trabalho e o eixo de inserção ou não inserção em uma sociabilidade sociofamiliar. Ao olharmos para a realidade brasileira, com tamanha desigualdade social, esses processos se dão constantemente por inúmeras rupturas, seja no vetor trabalho ou na sociofamiliar.

O estudo científico mais recente em relação ao tema foi publicado em maio de 2020 , divulgando o Relatório Final com os resultados da pesquisa desenvolvida no âmbito do projeto “Conhecer para Cuidar”, uma parceria entre a Associação Beneficente O Pequeno Nazareno e o Centro Internacional de Estudos e Pesquisas sobre a Infância da Pontifícia Universidade Católica do Rio de Janeiro (CIESPI/PUC-Rio). A pesquisa possibilitou a coleta de um rico e inédito conjunto de dados quantitativos e qualitativos sobre crianças e adolescentes (7-18 anos) em situação de rua e em Acolhimento Institucional, investigando a realidade de 17 cidades brasileiras com mais de 1 milhão de habitantes.

De acordo com o Censo do Sistema Único de Assistência Social (SUAS), do ano de 2018, haviam 526 unidades de acolhimento no país, sendo que 257 eram governamentais e 269 eram organizações da sociedade civil. Os dados do Censo destacam que havia cerca de 1.521 crianças e adolescentes acolhidas, que haviam vivido pela rua em algum momento da vida.

A amostra da pesquisa contou com 283 crianças e adolescentes em situação de rua e 271 que estavam em Acolhimento Institucional e tinham trajetória de vida nas ruas. Nas ruas, $45 \%$ dos participantes se declararam pardos; $40 \%$, negros; $12 \%$, brancos; $2 \%$, indígenas; e $1 \%$, amarelo. A grande maioria de negros e pardos na amostra é reveladora: juntos, compõem $85 \%$ dos participantes.

Os dados relacionados à escola representam um grande desafio a ser enfrentado pelo Estado e instituições, pois dos sujeitos entrevistados nas ruas, $42 \%$ afirmaram não estar frequentando a escola no momento da pesquisa. No acolhimento, 30\% disseram o mesmo. Daqueles que vivem nas ruas e frequentam a escola, $58 \%$ referiam estar no ensino fundamental, o que sugere uma grande defasagem idade-série.

Importante salientar que o documento anteriormente referido traz as melhorias almejadas para o futuro relacionado aos estudos, onde as respostas apontavam para um desejo de: "estudar em escola melhor, com professores e merenda"; "voltar pra escola, ter $2^{\mathrm{a}}$ via de Revista Interinstitucional Artes de Educar. Rio de Janeiro, V. 7, N. 1 - pág. 45-59 janeiro-abril de 2021: "Pedagogias Vitais: Corpo, Desejo e Educação" DOI: 10.12957/riae.2021.54954 
documentos e participar de Jovem Aprendiz"; "fazer curso profissionalizante"; e "ter formação de nível superior". O serviço de Acolhimento Institucional é o que mais aciona o campo da Educação, de acordo com a pesquisa, e em relação aos equipamentos da saúde e assistência social.

Todo esse acúmulo de pesquisas, dados e informações demonstram que a educação formal ocupa um papel de destaque nos discursos e histórias de vida das crianças e adolescentes em situação de rua, porém muito permeado por práticas de exclusão e insucesso. Nesse sentido, é explicito que o aspecto de engajamento individual acaba por inviabilizar o papel do Estado e da sociedade em proporcionar proteção a essas crianças e seus direitos.

Paulo Freire (1996), quando escrevia sobre o ato pedagógico, já esclarecia que o diálogo, a comunicação e a reflexão eram princípios para o aprendizado, numa relação em que o professor e o aluno são sujeitos desse ato. Nesse sentido, a Educação Popular traz um outro sentido à educação. Um espaço como a rua, possibilita ecos entre as vozes que passam por ela, incentivando e propiciando que participem do processo pedagógico.

Para adotar o termo "trajetória" utilizado neste estudo a defesa é a partir de Paulo Freire (2018), com Pedagogia do Oprimido, onde afirma que o homem diferentemente do animal, não somente vive, mas existe, e sua existência é histórica, e se dá pela relação homem-mundo. Cada “corpo consciente" traz consigo os significados e sentidos por onde passa, e nesta circunstância de pesquisa, a família, a rua, a escola e outras instituições serão contextos importantes de investigação e descobrimento.

Já para conceituar "trajetória escolar" utilizaremos Nogueira e Fortes (2004) que trata o termo "trajetória" na linguagem cotidiana como caminho, percurso ou trajeto. Ainda podemos pensar no deslocamento entre um ponto e um objeto, no caso do ponto em questão, podemos situar o aluno e o espaço de referência sendo o sistema de ensino. "A noção de trajetória escolar diz respeito, então, aos percursos diferenciados que os indivíduos ou grupo de indivíduos realizaram no interior dos sistemas de ensino" (NOGUEIRA, FORTES, 2004, p. 59).

Nesse cenário, precisa-se ampliar a noção de Educação, assim como afirma Mészáros (2008, p. 53), em crítica à Educação Formal:

Nunca é demais salientar a importância estratégica da concepção mais ampla de educação, expressa na frase: "a aprendizagem é a nossa própria vida". Pois muito do nosso processo contínuo de aprendizagem se situa, felizmente, fora das instituições educacionais formais. Felizmente, porque esses processos não podem ser manipulados e controlados de imediato pela estrutura educacional formal legalmente salvaguarda e sancionada. 
O direito à educação é um tema já pesquisado na literatura, porém segundo a pesquisadora Irene Rizzini (2019), no que tange a população infantil e adolescente em situação de rua o tema ainda é obscuro. A saída da escola está ligada a uma grande dimensão de fatores que não se reduz apenas à dimensão econômica. Nota-se um esforço por parte das crianças e adolescentes e de suas famílias para continuar sua escolaridade, o que contraria segundo a pesquisadora, o senso comum de que as famílias mais empobrecidas dão menos valor à educação de seus filhos.

\section{As Políticas Públicas para Crianças e Adolescentes em Situação de Rua}

A sociedade, ao lidar com crianças e adolescentes em situação de rua, não enxerga que houve um fracasso das redes de proteção, inclusive da própria sociedade. Nesse contexto, as crianças nessa situação estão imersas num processo de marginalização e criminalização, sem ao menos ter o direito de um nome, são chamados de coitados e desamparados ou "menores", "delinquentes", ou "pivetes" que colocam em risco a vida dos cidadãos de bem, e a partir de então, tornam-se problemas para a Segurança Pública (NASCIMENTO, 2002; PAIVA et al, 2016).

Esses estereótipos são reforçados pelo fato de que muitas vezes as crianças, adolescentes e jovens em situação de rua fazem uso abusivo de drogas, na tentativa de aliviar um sofrimento, fato não discutido enquanto demanda social, além da vulnerabilidade socioeconômica, evasão escolar, abuso e exploração sexual, trabalho infantil, abandono, negligência, entre outros. Para pensar e refletir sobre a situação de adolescentes e jovens usuários de drogas, Paiva e colaboradores publicaram, em 2016, um texto que aponta a necessidade de uma reflexão ampliada envolvendo os serviços de saúde, assistência social, órgãos do poder judiciário e conselhos tutelares, mesmo com a implementação prévia de algumas políticas no sentido de articulação de setores, como o ECA em 1990, Plano Nacional de Convivência Familiar e Comunitária em 2006, Sistema Nacional de Atendimento Socioeducativo (SINASE) em 2012, essa reflexão ampliada ainda acontece com pouca frequência.

No âmbito educacional os desafios continuam, pois não é necessário apenas garantir o acesso, e sim a permanência desses indivíduos. Silva (2005) em pesquisa com adolescentes "abrigados" estuda a relação entre o "mundo da rua" e o "mundo da escola". O estudo evidencia 


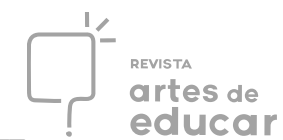

que é necessário alterar a organização da escola tradicional, e principalmente as relações dentro dela, sua lógica de seriação, seletividade e avaliação faz com que a escola não seja uma possibilidade para esses adolescentes.

Ainda de acordo com o Projeto Conhecer para Cuidar (2020) quando perguntados sobre quais as expectativas de melhorias almejadas para o futuro a opção "oportunidades de estudo" foi a segunda categoria mais selecionada tanto pelos participantes que vivem nas ruas como no acolhimento, embora mais de 1/3 dos entrevistados está fora da escola.

\section{Considerações finais}

A corporeidade de uma criança em situação de rua deve ser observada com um olhar cuidadoso adotando a pedagogia da diferença, de modo que promova corpos potentes, criativos, alegres e livres. Fico satisfeito ao perceber que a prática circense foi um conteúdo com significado para essas crianças e adolescentes. O caráter pedagógico da atividade pode ter sido fator desejante de intenções que tragam essas crianças para ambientes de proteção social, no qual elas se sintam acolhidas e cuidadas.

A desigualdade social produz muito fome, miséria e morte no Brasil. O Estado do Rio de Janeiro escancara isso todos os dias com tanta violência que surge e ultrapassa nossos corpos. A população negra que mora em comunidades é a que mais morre, devido a um sistema que promove guerras visando gastos excessivos com segurança pública. Ao mesmo tempo que escolas estão sendo fechadas e precarizadas pela falta de repasse de recursos.

As políticas públicas sociais estão sendo ameaçadas e o trabalhador vem sendo prejudicado com o desmonte do Sistema Único de Saúde (SUS) que acaba fazendo muito com o pouco recurso que recebe. As escolas cada vez mais vêm perdendo seus alunos para o tráfico de drogas e é jogada a responsabilidade a família de maneira equivocada, e não ao Estado que remunera mal seus professores, que não coloca escolas em tempo integral com atividades interessantes para os alunos.

Olhar o corpo e o contexto no qual se vive é uma perspectiva de luta para mudarmos essa realidade. A exclusão social contribui diretamente na evasão escolar dos estudantes pobres e da periferia. Ou seja, a luta está em garantir uma sociedade menos desigual e cobrar do estado à saúde e à educação gratuita e de qualidade que todos e todas têm direito pela constituição federal. 


\section{REFERENCIAS}

BRASIL. Lei 8.069 de 13 de julho de 1990. Estatuto da Criança e do Adolescente. Disponível em: http://www.planalto.gov.br/ccivil_03/leis/18069.htm

CASTEL, R. As armadilhas da exclusão social. In: CASTEL, R., WANDERLEY, L. E. W., BELFIORE-WANDERLEY, M. Desigualdade e a questão social. $2^{\mathrm{a}}$ ed., p.17-50, São Paulo: Educ; 2004.

DAOLIO, J. A construção cultural do corpo humano. In: DAOLIO, J. Da cultura do corpo. Campinas: Papirus. 1995. p. 31-49.

FREIRE, P. Educação na cidade. São Paulo: Olho d’Água, 2006.

FREIRE, P. Pedagogia da Esperança: um reencontro com a pedagogia do oprimido. $11^{\circ} \mathrm{ed}$. Rio de Janeiro: paz e terra, 1996.

Pedagogia do Oprimido. 65 ed. Rio de Janeiro/São Paulo: Paz e Terra, 2018.

LOURO, G. L. Currículo, gênero e sexualidade: o "normal", o "diferente" e o "excêntrico". In: LOURO, G. L.; NECKEL, J. F.; GOEELNER, S. V. (Orgs.). Corpo, Gênero e Sexualidade: um debate contemporâneo na educação. Petrópolis: Vozes. 2003. p. 41-52.

MÉSZÁROS, I. A educação para além do capital. 2 ed. São Paulo: Boitempo, 2008.

NASCIMENTO, M. L. do (Org.). Pivetes: a produção de infâncias desiguais. Rio de Janeiro: Oficina do Autor, 2002.

NOGUEIRA, C. M. M.; FORTES, M. de F. A. A importância dos estudos sore trajetórias escolares na Sociologia da Educação contemporânea. Paidéia/FUMEC, ano III, nº 2, 2004.

OLIVIER, G. G. F. O corpo vivido, o corpo no mudo. In: OLIVIER, G. G. F Imagem Corporal, Consciência Corporal e Corporeidade. Ijuí: Unijuí, 2000. p. 35-64.

PAIVA, I. K. S. de.; LIRA, C. D. G.; JUSTINO, J. M. R. et al. Direito à saúde da população em situação de rua: reflexões sobre a problemática. Ciência Saúde Coletiva, Rio de Janeiro, v. 21, n. $8, \quad$ p. 2595-2606, 2016. Disponível em <http://www.scielo.br/scielo.php?script=sci_arttext\&pid=S1413- Acesso em: 28 set. 2020.

PROJETO CONHECER PARA CUIDAR - Relatório final do levantamento de dados quantitativos e qualitativos sobre crianças e adolescentes em situação de rua e em Acolhimento Institucional como medida protetiva à situação de rua. Maio, 2020. Disponível em: https://www.neca.org.br/arquivos/9708 Acesso em: 10 ago. 2020.

SAUCEDO, I. A.; TARACENA, B. E. Habitar la calle: pasos hacia una ciudadanía a partir de este espacio. Revista Latinoamericana de Ciencias Sociales, Niñez y Juventud, v.1 n.9, p.269-285, 2011. Disponível em https://www.redalyc.org/articulo.oa?id=77320072014. Acessado em 25 ago. de 2020. 
SILVA, S. C. A escola e a rua: interação possível? Revista de Ciências Humanas. Florianópolis: EDUFSC, n. 37, p. 67-87, abril, 2005.

TRINDADE, A. L. Do corpo da carência ao corpo da potência: desafios da docência. In: Garcia, R. L. (Org.).: O corpo que fala dentro e fora da escola. Rio de Janeiro: DP\&A, 2002. p. 65-88.

\footnotetext{
${ }^{\text {i }}$ Graduado (Licenciatura) em Educação Física pela Universidade Estadual de Goiás (ESEFFEGO/UEG) e (Bacharelado) na UNIVERSO-RJ. Mestre em Saúde Coletiva pela Universidade Federal Fluminense-UFF (2019), em Nitéroi-RJ, participa do projeto de extensão Crianças e adolescentes em situação de rua e acolhimento institucional: construindo estratégias de territorialização afetiva. Atualmente, professor de Educação Física da Educação Básica e Assessor Pedagógico do Programa Municipal de Educação Integral de Tempo Integral, ambos em Maricá. ORCID iD: https://orcid.org/0000-0001-6176-3309

ii O projeto Ocupa Praça é uma das atividades dentro do projeto de extensão chamado Crianças e Adolescentes em situação de rua e acolhimento institucional: construindo estratégias de territorialização afetiva, vinculado ao Instituto de Saúde Coletiva da UFF. Tal projeto acontece mensalmente em conjunto com equipamentos da saúde mental e assistência social de Niterói, e atualmente está suspenso devido as imposições da pandemia COVID 19. iii Desfiliação é entendido como a uma das zonas do processo de vulnerabilização, onde o sujeito rompe com os vínculos familiares. Porém esse processo de desfiliação não é único, e na rua possui diferentes formas de existência social devido suas diferentes formas de inserção relacional e no mundo do trabalho. Exemplo: a maioria das crianças e adolescentes em situação de rua estão sem a presença de um adulto responsável.
} 